Portland State University

PDXScholar

$10-2016$

\title{
Provider Perspectives on Principle-Adherent Practice in Empirically Supported Interventions for Emerging Adults with Serious Mental Health Conditions
}

Janet S. Walker

Portland State University

Katherin M. Flower

Portland State University

Follow this and additional works at: https://pdxscholar.library.pdx.edu/socwork_fac

Part of the Social Work Commons

Let us know how access to this document benefits you.

\section{Citation Details}

Walker, J.S. \& Flower, K.M. J Behav Health Serv Res (2016) 43: 525. doi:10.1007/s11414-015-9465-8 1

This Post-Print is brought to you for free and open access. It has been accepted for inclusion in Social Work Faculty Publications and Presentations by an authorized administrator of PDXScholar. Please contact us if we can make this document more accessible: pdxscholar@pdx.edu. 


\title{
Provider Perspectives on Principle-Adherent Practice in Empirically-Supported Interventions for Emerging Adults with Serious Mental Health Conditions
}

\author{
Janet S. Walker \& Katherin M. Flower.
}

\begin{abstract}
In recognition of the need to create new treatment approaches that will be appealing to and effective for emerging adults with serious mental health conditions, researchers have begun to create and evaluate programs and interventions that are specifically tailored to reflect the preferences and needs of the population. The literature that describes these new approaches-including both descriptions of interventions and guidelines based on expert consensus - expresses a high degree of agreement regarding practice principles that should guide intervention. However, beyond naming these principles, the literature provides little information about what the principles mean, or how principle-adherent practice can be recognized. This article describes a qualitative investigation of providers' understanding of principle-driven practice in the context of programs and interventions for emerging adults with serious mental health conditions. The goal was to learn about how providers conceptualize the principles that drive their practice, and how they describe principle-adherent practice.
\end{abstract}

\section{Introduction}

The term "emerging adulthood" was coined at the turn of the millennium to describe the increasingly lengthy period in young people's lives between the end of adolescence and the attainment of various milestones of adulthood, such as completing one's education, establishing a career, achieving financial independence, marrying and starting a family. ${ }^{1}$ This stage of life is characterized by exploration and instability, and brings both opportunities and challenges as young people transition into the roles and relationships of mature adulthood. For emerging adults who experience serious mental health conditions (SMHCs), the challenges tend to be particularly pronounced. Relative to their peers, emerging adults with SMHCs tend to experience worse outcomes in a variety of domains, including education, vocation, and community integration..$^{2-4}$ These studies point to an unmet need for effective services, however, there is also evidence that the services that are currently available tend not to be either engaging or developmentally optimal for emerging adults with SMHC. ${ }^{5-7}$ As adolescents approach age 18-when they are still eligible for children's services but presumably have more control over decisions about whether or not to access them-their use of mental health services steadily declines, 6 and young adults are less likely than other adult cohorts to access treatment. ${ }^{5,8}$

In recognition of the need to create new approaches that will be appealing to and effective for emerging adults with SMHCs, researchers have begun to create and evaluate programs and 
interventions that are specifically tailored to reflect the preferences and needs of the population. ${ }^{9-16}$ However, the research base for effective interventions and programs, while growing, is currently quite small, and evidence for effectiveness remains somewhat limited. In an effort to move the field forward in the absence of a robust evidence base, several national level initiatives have engaged experts in examining relevant literature in order to produce guidelines and recommendations regarding core components that should be included in programs designed to improve outcomes for emerging adults who have SMHCs. ${ }^{17-25}$

One notable aspect of this literature-including both the descriptions of interventions and the guidelines based on expert consensus-is that an important subset of these sources expresses a high degree of agreement regarding characteristics of promising approaches for improving outcomes for young people with SMHCs. ${ }^{10,26,27}$ Furthermore, this agreement is apparent across the various sources, regardless of what types of outcomes-e.g., employment or career development, education, mental health, community integration-are the primary focus of the programs or interventions that are being discussed. First, the approaches generally are described as being structured around an individualized, person-centered planning process that engages the emerging adult in working towards personally meaningful goals. Additionally, the recommended approaches share a number of general principles. For example, the planning process is intended to be developmentally appropriate, strengths based and driven by the young person's perspectives and priorities. Additional widely-shared principles stress the importance of developing self-determination skills, and building relationships and/or social capital, through connections to supportive adults and peers, and to other development-enhancing contexts.

Despite expressing agreement on a general approach and key principles, this literature-including both the research reports and the expert consensus guidelines-does not offer much in the way of detail about how providers actually implement the recommended features in practice. Having more detail will be important for efforts to create or adapt services based on the guidelines, particularly given the uncertainty that has historically existed regarding the definitions and descriptions of several of these key intervention ingredients. For example, there is no widely-accepted definition of what constitutes a person-centered planning approach, and there is a documented lack of clarity as to exactly what the implications are for provider behavior when principles call for practice that is developmentally appropriate, strengths based, driven by client perspectives, and/or focused on building social support, community connections or "informal support." ${ }^{28-35}$ Implementation science has converged on the view that achieving conceptual clarity regarding intervention program principles and values a prerequisite for effective staff training, coaching, supervision and evaluation, which in turn are core components or "drivers" of successful program implementation and replication. ${ }^{36-38}$

Clarification of the principles-and descriptions of principle-adherent practice-may be helpful for efforts to develop interventions or programs based on current understanding of best practice; however, it may also be important to clarify how possible contradictions between the various principles can be reconciled. One important area in which contradiction may arise is in relation to the recommendation that intervention work should be driven by the client's perspectives and priorities. Yet it is unclear exactly how this principle is to be reconciled with the fact that each program is seeking specific kinds of outcomes for the young people that are being served. This includes not just longer term outcomes such as having a job or a safe place to live, but also more proximal or mediating outcomes implied by the principles, such as building strengths or increasing connections to positive peers, supportive adults, or development-enhancing contexts. In other words, how do practitioners undertake their work with young people in a manner that is both person-centered and (at least to some extent) directive?

The study described here was a qualitative investigation of providers' understanding of principle-driven practice in the context of programs and interventions designed to improve outcomes for emerging adults with serious mental health 
conditions. The purpose of the study was to learn about how providers conceptualize the principles that are intended to guide their practice, and how they identify and describe principle-adherent practice. Additionally, the study aimed to examine the extent to which providers' definitions of the principles were similar to and/or different from the definitions given in the research literature and practice guidelines.

\section{Method}

The current study was conducted as part of a larger effort to develop a conceptual model and theory of change describing how practitioners use a positive developmental approach in their work with emerging adults with serious mental health conditions. ${ }^{26,27}$ Prior to undertaking the current study, the research team had undertaken a literature review, which led to a draft conceptual model and a draft list of elements and principles that were widely used/recommended in the literature. In these materials, the research team proposed that these shared elements and principles described a positive developmental approach to working with emerging adults. The draft materials were circulated to ten expert stakeholders nationwide for review. The stakeholders included researchers-specialists in developmental theory and in emerging adult mental health intervention-and administrators in empirically supported programs, as well as young people who had received services from these programs, and their family members. Based on feedback from stakeholders, a new iteration of the theoretical model was developed; however, the principles remained essentially unchanged at this point.

The current study, along with a companion study that sought perspectives of young people who had been served by empirically-supported programs, was conducted as a means of gaining insight into how providers conceptualize their work in terms of the principles that are widely seen as driving effective practice with young people with SMHCs. Initial analyses of the material from the provider and emerging adult interviews were used as a basis for developing yet another iteration of the model and principles. The resulting work was the focus of intensive, structured discussion during a day and a half meeting of stakeholders. ${ }^{26}$ Discussions were designed to focus on the appropriateness of the model itself, the findings from the provider/ emerging adult interviews, and the most challenging issues that had been identified with regard to successful model implementation. Final analyses of the interview material were then conducted in light of the theory that was developed and validated through the prior steps of this process.

The current study of provider perspectives included a purposive sample ${ }^{39}$ of practitioners who were experienced and effective, who worked with young people from diverse backgrounds, and whose work was informed by practice principles consistent with an overall positive developmental approach. To obtain the sample, the research team began by contacting programs that were implementing empirically-supported interventions that were designed specifically to serve emerging adults with SMHCs. The research team worked with program administrators to identify their most experienced and effective practitioners, and to select from this group a sample of practitioners who worked successfully with young people whose social identities varied in terms of socio-economic status, sexual identity, systems involvement and race/ethnicity. The goal was to generate an overall sample of providers who worked with young people from a diversity of backgrounds. For smaller programs, one practitioner was recruited for participation in the study. For larger programs-i.e., those implemented statewide and/or nationally-two practitioners from geographically distinct programs were identified and recruited. Interviews were conducted either in person, at the practitioner's workplace, or by telephone. All of the providers who were recruited participated in interviews for the study. Practitioners were paid an honorarium for their participation.

Eleven providers were interviewed for the study. Among these, three were male. Two identified as Latino, one as African-American, and one as Native American (Navaho). Two served young people in sparsely populated rural areas, two worked with young people in small cities and the surrounding rural areas, and the remainder worked with young 
people primarily in cities and/or suburban areas.

A semi-structured interview protocol was developed to guide the interviews, all of which were conducted by a single researcher. The providers were given the interview questions, as well as a draft list of principles and definitions, prior to the interview. The first section of the interview asked briefly about the population of young people that the provider worked with. The remainder of the interview focused on the principles and principle-driven practice. First, providers were asked to select from the list the three "top" principles that they thought were most central to their work and to describe how they used each of the three in their work with young people. They were also asked if they would change the wording of any principle or its description, and whether there were principles on the list that they felt did not belong, or principles that they believed were missing. Most of the remainder of the interview consisted of probes that asked the providers to give specific examples of "pieces" of their practicei.e., intervention steps or activities, types of interactions, procedures-that exemplified the practice principles "in action."

Theoretical thematic analysis ${ }^{40}$ was utilized in this study. The purpose of this approach is to allow the analysis to be guided by relevant themes or theory, but also to remain open to information that challenges existing understanding. One of the two coders who worked on the analysis was deeply involved in the conceptual model-development work that were the focus of the larger project of which the current study was a part. The other coder was oriented to that work prior to beginning work on the analysis. Thus, the analysis team sought to incorporate both knowledge of the existing theory and "new eyes" capable of giving a fresh perspective.

Interviews were transcribed and entered into ATLAS.ti software ${ }^{41}$ for analysis. The analysis began with each of the two coders working independently, first reviewing all of the transcripts, and then using selected portions of several transcripts to develop preliminary codes. The coders then worked together to merge the two sets of codes and to refine the code definitions. They then again worked independently to recode portions of several interviews, using a constant comparison process and reviewing quotations, codes and code groupings, and updating the code book to reflect jointly made decisions. At the point where the code book was relatively stablei.e., codes were not being added and refined each time a new interview portion was reviewed, the coders began final coding of the interviews. Each of the two coders independently coded an interview, then the pair met to discuss the codes, reconcile, and update the code book. This process was repeated until the pair had very consistent agreement on the coding. At this point, one coder took over primary coding, with the other coder reviewing the codes and responding to memos regarding any uncertainty. Any disagreements or uncertainties were resolved collaboratively, and modifications were made to the code book when deemed necessary.

\section{Results}

The providers described the populations they worked with as comprised of young people in their late teens (16 or older) through their mid-twenties (24 or 25 years old). Three providers described the populations they worked with as being predominantly White, while the other providers described working with populations that, while mixed in terms of race or ethnicity, were predominantly African-American, Latino or Native American. Two providers noted that the populations they worked with included substantial numbers of young people whose parents were immigrants and two providers noted youth in foster care or young adults who had transitioned out of foster care as forming a significant portion of their caseloads. Other providers described their caseloads as including substantial numbers of young people who were homeless, gang affiliated, or LGBT/questioning (lesbian, gay, bisexual, transgender or questioning their sexual/gender identity). One provider noted that she frequently worked with young adults who had been identified as having cognitive challenges.

As stated previously, one of the main goals of the study was to understand how providers conceptualize the principles. When asked specifically about the principles, the providers generally endorsed the list they were given prior to the interview, and 
suggested few additions or wording changes. As they further discussed the principles and how the principles guided their work, however, they provided information that both explicitly and implicitly reflected on the principles. Thus, the process of coding the interviews yielded quite a bit of additional information that was used to clarify the definitions of the principles and to make them more conceptually distinct from one another. The final list of principles, together with their definitions and sample quotations, is provided in Table 1. Providers are identified by the initial letter(s) of their first names.

Table 1. Principles and examples from provider interviews

Principle: Description

Examples

Put the young person in the lead: Elicit and clarify the young person's perspectives and priorities, and ensure that these drive the work.

...it's really important with the program that I'm in. You really have to have them buy into what they want to do. We try to empower them and when we first start off ... we ask them what do they want out of the program, what are their goals, and we try to focus on that. Whether we agree on it or not, or whether we believe that they can reach it or not, it's the starting point. (I)

And if they have no idea [about taking out a loan], then I can say this is what I know about loans, this is what I've seen, but ultimately this is up to you. It's your choice, but there are consequences for the choice you make. Whether it's good or bad. So they're still in the lead. I'm not telling them not to do it. (B)

It means they are able to come to the table and be involved with us because of things they want and find meaningful and that sets the tone for their work with us. If there's not something they've identified as meaningful, it's hard to justify the work. (L)

I might have an idea, but it's really not about what I think, it's what they want to do. (R)

Build trust: Have, and demonstrate, a genuine appreciation for the young person and his or her thoughts and ideas, as well as a genuine commitment to the idea that the young person has the ability to take charge of his own life and move it in a positive direction.

Because if they're sharing it with you, it needs to be validated and respected or they're not going to share any more. (As)

There s a certain honesty that comes with ... doing it genuinely. If you don't have it they'll know it. So that's a principle, an inward principle that is often overlooked, but I can see it in meetings, that there is [another provider] with an inward issue that they need to address. (D)

There's a power differential between adolescents and adults and that automatically implies a need for head-butting or resistance because developmentally they are really deciding for themselves what they believe or their values are. So as an adult I can understand that they are doing that and show that they're smart and capable that starts from a place that moves forward rather than having to go through this tension (S)

Young people are keen observers of human behavior and adults, and whether or not we're trustworthy or honest or going to pull a power trip. Or see them for who they are especially because their identity is so core to this stage of life. So in holding that place, where I see them and approach them as fundamentally good no matter what is going on, supports the earning of trust, which I hold really strongly, so I tell the young people that my expectation of myself is that l'll be earning trust each day. $(K)$ 
Table 1. Principles and examples from provider interviews [continued]

Guide without leading: Support a young person's positive development and movement toward personally meaningful goals, without attempting to dictate decisions or outcomes.

...guide without manipulation, I might add to this, and I think it is a challenge for clinicians-also this idea you are on a journey with someone and you're not invested in the outcome, you want the outcomes they want but not too wedded to your idea of what success would look like. Not every client comes to us and says they want to be symptom free, so we try not to put our own ideas on what we'd like to see them attain. (L)

That it is a skill to decide to do what I call stepping back so they can step up. So when I step back so they can step up, usually they do step up and make the correct decisions, but it requires me to really take my time and make sure they understand their decision making at different levels. So I might even use some reflective listening so they know l'm understanding them, and then...And I might ask them, so tell me how you think that's going to help you with your goals, so I'm making sure they understand the total ramifications of their decision. (D)

We are not trying to force some kind of service down their throat, but listening to where they're at and spending time to understand their situation, understand their past, and be able to limit our opinions and really listen to them and work for what they feel at that time, and be able to teach them along the way. (B)

I want to acknowledge what they want by allowing them the opportunity to put them in the lead, but also have to guide them by opening opportunity and reinforcing their confidence in what they want to work on. [That] balance also helps them learn how to lead. I offer options all the time, but they don't know what they want to work on. So I create [a bunch of] options based on their cues and offer that and let them choose. (S)

I may push someone to try something they've said they are interested in. I always make sure to identify it out loud. I don't want you to do it because I say, but you have mentioned in the past, here are some of the things you've said. Part of being self-determined is telling people what you want so I encourage you to say whether that's what you want or not. (J)

Model and teach skills: Model and teach skills, including skills for self-determination, skills for daily living, and skills for building connections to important interpersonal contexts.

Have the ability to practice for that so there's some preparedness for them. It's a lot of teaching... it's just me working one-on-one and teaching and looking at the whole picture so that they can have more of an informed choice of what they want to do with their lives. (Al)

They keep this in the binder, and we refer back and add it to the list. Tracking information is a skill we are really trying to teach. $(\mathrm{J})$

...modeling and teaching skills is super important. That's what's going to take them beyond the intervention. I can't leave that out. So even didactic learning for skills that they can apply, and they internalize those. Most important skills, identify what they want, break it down into bite sized pieces and getting help and support, knowing how to ask for help. (S)

And even with that, just helping them build connections, these are skills that can transfer over in to interpersonal relationships, meeting new people, how to connect with others, communications skills, all these things that can transfer to different areas of their lives. (V) 
Table 1. Principles and examples from provider interviews [continued]

Build positive connections: Assist the young person in building and using connections to supportive people and contexts.

Informal supports, family and friends, making them understand that these are the people that are going to be there for the long haul and making sure that they use them in the appropriate manner and how they can follow through. (I)

I encourage them to ask other people what they think about these things_-talk to people that you trust that's important. (J)

Sometimes they can get to a point where they can build trust with a particular service provider...and then adapt that to other scenarios and other folks in their lives. Start with building trust with me, then helping the youth build trust maybe a rehab counselor or a teacher if they're starting school so they can see they do have connections in the community, there's other people on their support network, and it can help them feel more secure. (V)

Building connections: It's just, if you have a support group, it facilitates, some of these people struggle, I want to be there to help them but I don't want to be the person that they always turn to, so if you can build a team around them-they make friends or connect with another agency-They have a different support group, and I'm their emergency contact or something. (R)

The model is huge in this one-building connections too, it helps with the connection to other families and their own families. For these young people, a lot of people in their lives can get burned out. There is a lot of anxiety. We are at the beginning of what can happen and it's a bit of a roller coaster. So the more we can connect them to community, to supports that can give them unconditional love, the better. (V)

Start where they're at: Promote learning, growth and development by understanding "where they're at," and/or helping to create the conditions so that the young person take new steps to gain knowledge, skills or awareness.

Just because the support you feel is supportive to them, if they're not ready to go there, we need to be respectful of that. (Al)

Some are able to enroll themselves in school, who are able to build some friendships, and we have youth for who even getting up in the morning, showering and leaving the house can be a struggle. Our youth are coming from backgrounds where they may have been dealing with psychosis, they may have mood disorders, substance use in the picture, the effects of trauma... all that impacts each very differently.... so we do work with them on meeting their needs on an individual basis, where they're at. (V)

...we are not trying to force some kind of service down their throat, but listening to where they're at and spending time to understand their situation, understand their past, and be able to limit our opinions and really listen to them and work for what they feel at that time, and be able to teach them along the way. (B)

They are going to talk to professionals, people outside of who they usually interact with, and they aspire to being like that person, but feel they don't have a lot of credibility in that area, and that may be intimidating. So, I say we can email, phone... you can do some things, or I can structure it, I could email or call first to open the door. Do you want to go in on your own, or go with me to meet them, or meet with me before and after? Some people don't want hand holding, so talk about the options and normalize it-everyone makes different choices and all these ways have worked for different people. You could start with more support the first time. ... Then do soft encouraging for the next interview for them to do more. (J) 
Table 1. Principles and examples from provider interviews [continued]

Recognize and work with strengths: Provide opportunities for the young person to develop an appreciation of his/her existing strengths and capacities, and to use and further develop these in the pursuit of personally meaningful goals.

...the strengths discovery, which is probably my favorite part ... in that it really lends itself to the client seeing that others can see them in a positive light and them feeling more comfortable with others in relation to that. A lot of youth I work with they are accustomed to service providers being more in relationship to the deficits in their life. (V)

...that really helps with the relationship because she sees me always looking at what she's doing good. For me to find those opportunities to celebrate her and to bring her family together... (D)

A positive message for them, a lot of them are consistently told what they don't do and deficiencies and their weaknesses, so whenever there is some sort of recognition of progress it helps out, it definitely Helps with their self-esteem and how they recognize themselves. (I)

[the assessment is] really guiding our work, and you learn so much from the youth. It actually assesses the youth's strengths based on the four quadrants of the medicine wheel: spirit, body, mind, context. (As)

Once we get that information from them, when we hear about opportunities in the community or know about resources that might foster some of those strengths, we definitely get them a connection with those opportunities and resources if it's something they are willing to do. (V)

Encourage discovery: Model and encourage young people to engage in exploration of new knowledge, ideas and experiences.

This is about brainstorming, looking into things, maybe you are lukewarm but find out more. Get the right information so you can make good decisions. If you don't go talk to someone, you really won't know-always looking for more information. So you can cross it off the list or look further. (J)

I think what's really important sometimes, not even medical in nature or even therapeutic, is having an outing, just exposing them... A lot of times they haven't been to certain areas or tried certain things. (I)

It's based on having looked at things together, and letting them experiment, attempt, explore, as appropriate to their culture. $(K)$

The second main goal of the study was to compare providers' conceptualizations of the principles to the conceptualizations provided in the research and practice literature that describes positive developmental approaches for working with emerging adults with SMHCs. As noted previously, when providers were asked to reflect on the principles and definitions that they had been provided with prior to the study, they generally endorsed the list that resulted from the literature review, and suggested only minimal changes. However, for four of the princi- ples, the process of coding the remaining interview material led to substantial revision of the principles' definitions. Thus there appears to be some level of discrepancy between how these particular principles are "officially" defined-i.e., in the research and practice literature-and how they are implicitly defined through providers' descriptions of their practice. The sections that follow describe how and why the definitions of these four principles were revised. This is followed by a discussion of what these findings might imply for further efforts to 
develop positive developmental approaches for working effectively with emerging adults with SMHCs.

Model and teach skills. The original definition of the "Model and teach skills" principle focused on efforts to help young people acquire skills that are important for self-determination. Self-determination has been defined as the ability to take selfdirected action to achieve personally meaningful goals, which in turn requires skills related to setting goals and making decisions, determining and carrying out actions consistent with those decisions, evaluating the results of those actions, seeking help when needed, exercising rights and responsibilities, and dreaming and taking risks. ${ }^{13}$ In some instances, the importance of these kinds of skills was described in the abstract:

...teaching skills is super important. That's what's going to take them beyond the intervention. I can't leave that out. So even didactic learning for skills that they can apply, and they internalize those. The most important skills: identify what they want, break it down into bite-sized pieces and getting help and support, knowing how to ask for help. (S)

In other instances, self-determination skills were referenced more concretely, often in descriptions of walking young people through a process for making specific decisions.

However, as coding proceeded, the category was expanded to include a variety or other types of skills that providers described or referenced. These included practical skills for everyday life, such as accessing and using transportation, or writing emails or making telephone calls. Skills related to building interpersonal connections and social support were also described.

So the more they have connections, the more support they have in the community, the better understanding they can get from folks who can support them in different ways for making those things happen. And even with that, just helping them build connections, these are skills that can transfer over in to interpersonal relationships, meeting new peo- ple, how to connect with others, communications skills, all these things that can transfer to different areas of their lives. ( $V$ )

On a few occasions, providers also referenced skills related to coping and managing emotions and mental health.

Sometimes I use a bit of CBT-primarily talking about cognitive distortions, how this impacts what they feel in certain scenarios, and what sort of behaviors come up for them and solutions to that... I might highlight certain things they say that could be reflective of a cognitive distortion. So I ask if they're interested in learning more about that, how we think about things can color how we view certain situations, how we act in them, how we feel in the moment. (V)

As these passages illustrate, the providers as a group referenced an extremely wide variety of different skills that they strove to teach to the young people with whom they worked, though any given provider typically mentioned only a small subset of skills. While this might reflect actual differences in what providers are trained to do in different program contexts, it also raises the possibility that providers are not given much specific direction regarding the skills that are most important for them to model and teach.

This possibility is reinforced by the discrepancy between the level of importance that was explicitly ascribed to "Model and teach skills"-i.e., by providers' nominations of "top" or most important principles-and the level of importance that was implicitly ascribed to this principle during providers' more open-ended comments. As described earlier, toward the beginning of the interview, participants were asked to identify their three "top" principles. Each of the principles was named as being among the "top" three by at least one provider. "Put the young person in the lead" was endorsed most frequently (a total of seven providers listed this among their top three), followed by "Build trust" (five nominations). The least frequently nominated principles were "Encourage discovery" (one provider), and "Model and teach skills" (three providers). 
This ranking of the principles by provider nomination was to some extent mirrored in their overall salience in the interviews (i.e., the relative frequency with which the coding categories referencing the principles were used). While the analysis did not have the aim of producing precise comparisons of saliency, general comparisons are still possible because of the very large differences in magnitude of usage of certain principles. "Build trust" and "Put the young person in the lead" were the most frequently used principles in coding overall; however "Build trust" was coded almost twice as many times (113 versus 60 coded segments across the interviews). "Encourage discovery" was coded fewest times overall. Only 16 segments-in only 6 of the 11 interviews-were tagged with this code.

On the other hand, a clear discrepancy in nominations versus salience emerged with respect to "Model and teach skills." While it was nominated as a top principle by only three providers, it was coded quite frequently (52 times, appearing in 10 of the interviews). This discrepancy suggests that the principle might be "misunderstood" in the sense that its importance in expert practice may be underestimated, even by the experts themselves.

Build trust. The "Build trust" principle also required multiple iterations of re-definition as the study progressed. In the original version that was presented to providers during the interview, this principle was named "Convey respect," and its definition referenced the need for providers to be able to truly see and appreciate the value of each young person. As coding proceeded, however, it became apparent that the core feature of this principle was not so much about simply conveying respect as it was about genuinely and honestly respecting the young person and his or her values and choices, including the choice not to receive services:

Just really letting them know that this is about them, I'm not here to force them to talk about things they don't want to, but if they do decide they want to talk about that then I'm a safe person. And then letting them know too, I've had the case where a person really doesn't want services and doesn't want to talk to me. I clarify my role, then I definitely respect that they don't want services at that point. But, since they have signed up, what that's going to mean is that I may call them from time to time just to see how they are, just to see if they want to meet, I don't want them to feel surprised if I contact them. (V)

Eventually, the coding for this category was extended to encompass an even broader idea of earning trust through being honest and transparent:

I think that's the most important part of the job is them being able to trust you, from the beginning, you say, everything we've talked about, everything we do is confidential, I won't talk about it with anybody unless you give me permission. If one of your goals, if we can get more help from another agency I won't do anything without your permission. Builds that relationship and that trust, and anything I have on them they're free to see anytime. (R)

Material coded as representing "build trust" also included occasions when providers stressed the importance of being honest and genuine regarding the interventions' principles, particularly the belief that emerging adults can and should take charge of their own lives, and that when they are given the opportunity to do so, they will be able to move in positive directions. By extension, this implies that the provider genuinely believes that the intervention works, and that by adhering to the principles, the provider is doing his or her best by the young person.

Young people are keen observers of human behavior and adults, and whether or not we're trustworthy or honest or going to pull a power trip. Or see them for who they are especially because their identity is so core to this stage of life. So in holding that place, where I see them and approach them as fundamentally good no matter what is going on, supports the earning of trust, which I hold really strongly, so I tell the young people that my expectation of myself is that I'll be earning trust each day. (K)

There's a certain honesty that comes with ... doing it genuinely. If you don't have 
it they'll know it. So that's a principle, an inward principle that is often overlooked, but I can see it in meetings, that there is [another provider] with an inward issue that they need to address. (D)

More than with other principles, providers described failures to act in ways that built trust. Usually, these were failures on the part of other providers:

In a lot of situations, clinicians, people on the treatment team, prescribers, they do not see the value in that. In respecting the client and their choices. They say they believe in [being] youth-driven, but it's obvious that don't really believe that this youth should be making any kind of decisions about their own life. (B)

Start where they're at. The principle "Start where they're at" ended up being frequently coded (46 times, appearing in 9 of the interviews), even though was not included on the original list of principles at all. Rather, this principle emerged from providers' descriptions of principle-adherent practice. Most of the material that was eventually coded as reflecting this principle started out being coded as representing "Encourage discovery." However, as coding progressed, it became apparent that the original definition of "Encourage discovery" contained two facets that were conceptually distinct.

Originally, any interview material that referred to the general idea of encouraging the young person to try or learn something new was coded as representing "Encourage discovery." However, as coding proceeded it was decided to distinguish between two different reasons for trying something new. First, trying something new was seen as an often playful or enjoyable way of expanding horizons or generating options. In this sense, discovery was an end in and of itself. Second, trying something new was seen as part of a learning process through which a young person gained new capacity or skill that was needed to move his or her goals or development ahead. The key that led to making this distinction was the repeated use of the phrase "meeting them where they're at" or "start where they're at" in the context of more focused and pragmatic learning. The use of this phrase was often very ex- plicitly associated with a developmental perspective on the part of the provider, who described how important it was to understand the young person's current level of development. This allowed the provider help the young person plan experiences with an appropriate level of challenge-and then provide support as needed-so that learning and development would move forward. The descriptions offered by the providers were quite consistent with the idea of instructional scaffolding-i.e., finding a level of challenge that just slightly exceeds the learner's level of skill, then providing support as new skill is tried out, and finally removing the support when the new skill is "set"-that has been a mainstay of education theory since the late $1950 \mathrm{~s}^{42}$ The skills or capacities that were associated with this code included both practical skills (e.g., setting goals, taking the bus, interaction with a prospective employer) and emotional skills (e.g., managing anxiety or anger, though these were less frequently commented on).

Many of my folks I will start...I'll just use phone calls as an example. I will start by making those calls with them, doing role plays, so they will know how to maneuver situations that they're trying to make phone calls on their own. And then from time to time I might start a phone call and then encourage them to also give their input, other times just sitting there for moral support while they're making their own calls asking about everything from enrolling for services, if it's a primary doctor or speaking with an advisor at a community college, or an adult school about how they can start classes... (V)

Material that was coded as referencing "Starting where they're at" was similar to, but also distinct from material that was coded "Encourage discovery." In segments that received the latter code, providers described the importance or provided examples of simply encouraging a young person to explore a new idea or experience or, more generally, to develop a mindset that is open to curiosity and exploration:

It's about being really curious... on the Internet, using tools for career research. Look at 
YouTube, Google things, email people and ask questions. Expanding their horizons. (J)

Guide without leading. The principle "Guide without leading" was included in the draft principle list given to providers prior to the interview. This principle emerged from the initial stakeholder review phase of the project, and it refers to the awareness that providers develop-and the strategies they use-to avoid the possible contradiction between the principle of "Put the young person in the lead" and the goal of achieving specific intervention outcomes. As noted previously, the outcomes that are sought through the interventions include longer term outcomes such as avoiding criminal behavior or making progress in the domain of education/ vocation, as well as more proximal or mediating outcomes implied by other principles, such helping the young person increase her appreciation of her own strengths and competence, or helping her build connections to supportive life contexts.

The "Guide without leading" principle has not been described in detail elsewhere, so its definition was largely built up from scratch on the basis of the interview material. In both their discussions of the principle (four providers nominated "Guide without leading" as among their top three principles) and the interview material more generally, providers described how they saw themselves as guiding a young person's decision-making process by helping him or her talk through the ramifications of certain courses of action without trying to manipulate or force the young person toward a specific point of view.

I think if we're sticking true to our belief in how this program really needs to run and the idea of voluntary and not doing it for them, but advocating and helping them make appropriate decisions. Then the [provider's] opinion is definitely not supposed to be given right off the bat. If I think you are making a terrible life decision and that's going to totally affect everything else, [then I ask them] to come up with examples of how this might impact something else, and use the conversation to steer them to maybe think about something and not make an immediate decision but ... to go through an adult thought process on how this is going to impact you in other ways. But ultimately we truly believe that the young adult, whatever the decision they make, we have to support and help them through regardless of whether we think it's right or wrong. (B)

Aspects of this decision support process are clearly compatible with, or even in some cases, explicitly drawn from, techniques that are central in Motivational Interviewing, ${ }^{43}$ a method that works to facilitate and engage a client's intrinsic motivation in order to promote behavior change. While MI is considered a client-centered counseling style, it is more directive than traditional client-centered approaches, and thus provides a model-either explicitly or implicitly-for guiding without leading. MI recognizes that clients are at different levels of readiness to undertake change, and uses non-judgmental, nonconfrontational techniques to help clients explore the costs and risks of particular behaviors, and the gains that may result from behavior change.

There's ways to [support decision making] that don't come off as this is your only option-it takes a certain demeanor-have them talk first and say their whole situation. It's ok to talk about your concern, but have to do it in a way that doesn't feel like they're being judged. With drugs and alcohol, there's one kid who was drinking Robitussen regularly. I try to give the realistic reality but also solicit that change talk to get him to the appropriate resources.... It's a little different than using MI completely with adults because some of [the young adults] don't have role models and people that are concerned about them or share their concerns, so you do need to guide it a bit more. Sharing your own concerns more but still leaving it open. (As)

Internally, my mantra is, "This is not my life." I have my own choices and goals and I can control what I do, not what they do. And I can't judge them, that is not my role. But I can help them slow down and think about their future. So the making decisions [process helps them] to slow down and think about it. Also we talk a lot about what do they think 
the key players in their life will say. Even if they don't respect their [treatment] team, the adults are gatekeepers who have a lot of power and control. Fair and not fair. How will your foster mom react? Not in a punitive way but in a way to get them thinking. If they want to drop out of school, ok, and usually if you ask them about why they want what they want, they have a rationale that makes sense. Like to drop out of school, "Tell me why," not "No, that's ridiculous, don't do it," and, "You're getting accommodations." But all that doesn't matter because they youth is telling me something opposite like they moved across town and they can't get to school on time. Then we can talk about compromise or learn how to communicate it effectively and how to address concerns. (S)

The "Guide without leading" code applied not only to descriptions of situations in which providers were supporting decision making, but also more generally to descriptions of how providers helped young people to gain a new perspective on various aspects of their lives. This was most obvious in discussions of strengths, like the examples provided in Table 1, in which providers described themselves as drawing out authentic talk from young people and helping them to see the strengths-related content. Providers also described helping young people plan activities, and supporting the execution of the activities so that young people would experience success. This kind of experience serves as an authentic demonstration of a young people's competence, and practitioners described how they debriefed with young people to foster an understanding what they had accomplished.

I continually point out that this is you not me. People are quick to appreciate and be grateful for help I give but I turn that around to say, "You're the person driving it-you decided that you wanted to do this rather than that, and that's why we got here." [I] reflect that a lot-it's their decisions and achievement. (J)

Providers used similar strategies to assist young people in building connections. By drawing out authentic talk about supportive relationships and structuring relationship- building or relationshipstrengthening activities, providers helped young people experience themselves as connected to people, organizations and institutions that could provide various forms of support.

\section{Implications for Behavioral Health}

In general, the interview material provided an endorsement of the set of principles laid out in $\mathrm{Ta}$ ble 1. Explicitly, the providers expressed agreement with the list of principles they were provided before their interviews. When asked to discuss specific elements of their practice, providers sometimes invoked the principles explicitly, and sometimes referenced them implicitly, through descriptions of their practice or through discussion of key concepts connected to the principles. Basic counts of providers' references to the various principles showed that all but two of the providers referenced each of the principles aside from "Encourage discovery" (which, as noted previously, was referenced by only six of the providers). Of the remaining two providers, one referenced all but one of the other principles, and the other all but two.

This underlying convergence across providers who are implementing different interventions raises the possibility that the interventions are actually specific examples of a more general approach that can be defined and described in terms of common elements (i.e., the steps, procedures or "pieces" that constitute a person-centered planning process) and factors (i.e., the general practice mode described by the principles). Attention to "common factors and common elements" approaches has intensified in recent years, specifically as a means of capitalizing more effectively on what is shared across allied sets of evidence-based, empirically-supported and promising practices designed for a particular population. ${ }^{44,45}$ Gaining clarity about common elements and factors can pave the way for efficiencies by creating cross-intervention opportunities to share assessments and assessment strategies; theoretical and conceptual models; intervention procedures, steps or activities; and training and workforce development strategies, all of which are very much needed 
to support efforts to improve outcomes for emerging adults with serious mental health conditions.

The current study can be seen as a first step in exploring a common factors and common elements approach to understanding positive developmental interventions with emerging adults with SMHCs. The study documents a set of shared principles, and uses the collective expertise of practitioners across a diversity of interventions as a means of developing definitions of the principles that are more detailed than what was previously available. These more detailed explications of the principles may contribute to a better understanding of what the principles actually mean, both conceptually and in practice. For example, the theme of building trust did not receive much attention in the literature reviewed for this study; however, the providers who were interviewed were unanimously emphatic regarding the central importance of trust building, and consistently reiterated that trust was a prerequisite for successful intervention. Furthermore, the interview material provided substantial elaboration regarding what providers believe they can do in order to build trust with young people. According to the providers, trust is built in part through concrete behaviors such as following through on commitments, affirming the young person's perspective verbally, and being persistent and consistently "there for" the young people. But providers also stressed that trust building was predicated on the providers' genuineness-not only their ability to genuinely respect young people and their perspectives, but also their genuine belief that, given the right kind of support, young people with serious mental health conditions take the lead role in steering their lives towards the futures they want for themselves. Several of the providers contrasted this genuineness to the mind set of colleagues from outside the program, thus implying the need to explore strategies to select and/or train for this capacity when building the workforce.

I think a tangible way our whole team does this, and I try to start off this way, we have a crucial part of our assessment that asks the young person and the family what's their explanation of what's gone on with them. I think that's a big way-it runs through our program-understanding how people conceptualize what's going on with them and valuing that. A lot of people don't even ask that, in my past jobs, it hasn't been something that happens... but you show respect by using the language they've chosen, why they know better than anyone else what's happening. (L)

Similarly, while providers gave many specific examples of ways that they scaffolded learning for young people by starting "where they're at," this general idea did not appear in any obvious way in the principles that are prominent in the literature reviewed for this study. This finding has at least two possible implications worth considering. First, that interventions might be strengthened by explicitly incorporating this principle into practice expectations, and second, that interventions and programs may benefit from using or adapting strategies for scaffolding learning that have been developed and tested in other contexts, particularly adult education.

The need for building skills, particularly selfdetermination skills, does appear in the literature reviewed for this study, though not in a particularly prominent manner. The providers who participated in the study only infrequently nominated "Model and teach skills" as a top principle; however, skill building was coded quite frequently throughout the interviews. As was the case for "Start where they're at," described above, this finding suggests that interventions and programs designed for emerging adults with serious mental health conditions may benefit by creating more explicit expectations regarding the importance of skill building generally, and by clarifying expectations about what kinds of skills should be built.

Another set of implications from the study concerns the difficulty that providers seem to have in describing specific practices-i.e., elements of the interventions-that exemplify adherence to the principles. Though the interview protocol consistently asked providers to give concrete examples of principle-adherent practice, the very large majority of "examples" were actually fairly abstract descriptions that essentially reiterated or elaborated on the principles. This finding suggests several possibilities with implications for behavioral health. First, 
it is possible that individual providers working with this population tend not to have a very wide repertoire of defined practice elements or strategies at their disposal. If this is the case, providers in allied interventions (such as those represented in this study) might benefit from sharing practice elements and strategies, thereby enriching their repertoires and thus their ability to tailor their approach to fit the unique needs and preferences of specific young people. Second, it is also possible that providers lack a clear understanding of exactly how their practice expresses the principles. If this is true, it suggests that providers might benefit from exposure to a clearly articulated conceptual model that describes in some detail what principle-adherent practice looks like, and how this sort of practice actually promotes positive outcomes. This sort of model does not exist in the literature reviewed for this study, and in fact, several researchers have commented that interventions for the emerging adult population lack a clearly articulated theoretical foundation. ${ }^{46-49}$ Helping staff come to an understanding of pathways to change is important for any intervention, ${ }^{50-52}$ but may be particularly crucial for comprehensive interventions-such as those represented in this study - that provide services and supports that are highly individualized. A theory-based understanding of practice can help staff to identify the "active ingredients" of their practice, and, presumably, to utilize these in a more intentional and impactful manner.

Finally, viewing interventions in terms of common elements and factors has potential implications for workforce development strategies, including pre- and in-service training and education. Few providers currently working in community mental health programs have been trained specifically to work with emerging adults, ${ }^{53,54}$ which implies a need to rapidly increase the number of practitioners prepared to deliver empirically-supported treatments for the population. However, most pre-service students preparing for front-line practitioner roles in mental health-regardless of their specific programs of study-are not trained to deliver empiricallysupported interventions. ${ }^{55}$ This is at least partially due to the ever-increasing number of interventions with evidence of effectiveness, and the difficulty of predicting which intervention(s) a student might be called upon to implement in his or her future employment. Statewide, regional or cross-agency inservice workforce development initiatives designed to increase the number of practitioners trained in empirically-supported approaches often encounter a similar stumbling block, i.e., that trainees' home agencies are implementing a diversity of specific interventions. If interventions designed to improve outcomes for emerging adults with SMHCs are, in fact, built around a core of shared elements and factors, then it would be possible for in-service and preservice training to focus on these. Trainees would then be gaining specific competencies relevant to serving the emerging adults, regardless of the specific interventions they might be called upon to implement. Training based around common factors and elements could thus enable the rapid expansion of a flexible workforce capable of responding effectively to the needs of emerging adults with SMHCs.

\section{Conflict of Interest}

The authors report no conflicts of interest.

\section{Acknowledgments}

This work was supported by funding from the National Institute of Disability and Rehabilitation Research, United States Department of Education, and the Center for Mental Health Services Substance Abuse and Mental Health Services Administration, United States Department of Health and Human Services (NIDRR grant H133B090019). The content does not necessarily represent the views or policies of the funding agencies. The author would like to thank all of the stakeholders who provided their insights and feedback for this work.

\section{References}

1. Arnett J. Emerging adulthood: A theory of development from the late teens through the twenties. American Psychologist 2000; 55(5): 469-480.

2. Davis M, Banks S, Fisher W, et al. Longitudinal patterns of offending during the transition to adulthood in youth from the mental health system. Journal of Behavioral Health Services \& Research 2004; 31(4): 351-366. 
3. Davis M, Vander Stoep A. The transition to adulthood for youth who have serious emotional disturbance: Developmental transition and young adult outcomes. Journal of Mental Health Administration 1997; 24(4): 400-426.

4. Vander Stoep A, Beresford S, Weiss N, et al. Community-based study of the transition to adulthood for adolescents with psychiatric disorders. American Journal of Epidemiology 2000; 152: 352-362.

5. Kessler R, Demler O, Frank R, et al. Prevalence and treatment of mental disorders 1990 to 2003. New England Journal of Medicine 2005; 352(24): 2515-2523.

6. Pottick R, Bilder S, Vander Stoep A, et al. US patterns of mental health service utilization for transition-age youth and young adults. Journal of Behavioral Health Services \& Research 2008; 35(4): 373-389.

7. US Government Accountability Office. Young Adults with Serious Mental Illness: Some States and Federal Agencies are Taking Steps to Address Their Transition Challenges. Publication No. 08-678, Washington DC: US GAO, 2008.

8. US Department of Human Services Substance Abuse and Mental Health Services Administration. What a Difference a Friend Makes: Social Acceptance is Key to Mental Health Recovery. SMA 07-4257, Washington DC: National Mental Health AntiStigma Campaign, 2007.

9. Walker JS, Gowen LK. Transition for youth with serious mental health conditions. In ML Wehmeyer, KW Webb (Eds). Handbook of Adolescent Transition Education for Youth with Disabilities. New York: Routledge, 2011, pp. 475-493.

10. Dresser K, Clark HB, Deschênes N. Implementation of a positive development, evidence-supported practice for emerging adults with serious mental health conditions: The Transition to Independence Process (TIP) Model. Journal of Behavioral Health Services \& Research, 2015; 42(2).

11. Hagner D, Malloy JM, Mazzone MW, et al. Youth With Disabilities in the Criminal Justice System: Considerations for Transition and Rehabilitation Planning. Journal of Emotional and Behavioral Disorders 2008; 16(4): 240-247.

12. Gilmer TP, Ojeda VD, Fawley-King K, et al. Change in mental health service use after offering youth- specific versus adult programs to transition-age youths. Psychiatric Services 2012; 63(6): 592-596.

13. Powers LE, Geenen S, Powers J, et al. My Life: Effects of a longitudinal, randomized study of selfdetermination enhancement on the transition outcomes of youth in foster care and special education. Children and Youth Services Review 2012; 34(11): 2179-2187.

14. Haber MG, Karpur A, Deschênes N, et. al. Predicting improvement of transitioning young people in the partnerships for youth transition initiative: Findings from a multisite demonstration. The Journal of Behavioral Health Services \& Research 2008; 35(4): 488-513.

15. Melton RP, Roush, SN, Sale, TG, et al. Early intervention and prevention of long-term disability in youth and adults: The EASA model. In K Yeager, D Cutler, D Svendsen et al. (Eds). Modern Community Mental Health: An Interdisciplinary Approach. New York: Oxford University Press, 2013, pp. 256-275.

16. Gowen LK, Bandurraga A, Jivanjee P, et al. Development, testing, and use of a valid and reliable assessment tool for urban American Indian/Alaska Native youth programming using culturally appropriate methodologies. Journal of Ethnic \& Cultural Diversity in Social Work 2012; 21:7 7-94.

17. Cobb RB, Lipscomb S, Wolgemuth J, et al. Improving post-high school outcomes for transition-age students with disabilities: An evidence review. Washington, DC: National Center for Education Evaluation and Regional Assistance, Institute of Education Sciences, 2013.

18. Fraker T, Rangarajan A. The Social Security Administration's Touth Transition Demonstration Projects. Journal of Vocational Rehabilitation 2009; 30: 223-240.

19. Blau GM, Caldwell B, Fisher SK, et al. The Building Bridges Initiative: Residential and communitybased providers, families, and youth coming together to improve outcomes. Child Welfare 2010; 89(2): 21-38.

20. Podmostko M. Tunnels \& Cliffs: A Guide for Workforce Development Practitioners and Policymakers Serving Youth with Mental Health Needs. Washington DC: National Collaborative on Workforce and Disability for Youth, Institute for Educational Leadership, 2007. 
21. Herz D, Lee P, Lutz L. Addressing the Needs of Multi-System Youth: Strengthening the Connection between Child Welfare and Juvenile Justice. Center for Juvenile Justice Reform, Robert F. Kennedy Children's Action Corps, 2013.

22. National Collaborative on Workforce and Disability. Guideposts for Success, Second Edition. Washington DC: Institute for Educational Leadership, National Collaborative on Workforce and Disability, 2013.

23. Luecking DM, Luecking RG. Translating research into a seamless transition model. Career Development and Transition for Exceptional Individuals. 2013: Advance online publication. doi: $10.1177 / 216514341$.

24. Koball H, Dion R, Gothro A, et al. Synthesis of Research and Resources to Support At-Risk Youth, OPRE Report \# OPRE 2011-22. Washington DC: Office of Planning, Research and Evaluation, Administration for Children and Families, US Department of Health and Human Services, 2011.

25. Marsenich L. A Road Map to Transition Services for Transition Aged Young Women: A Research Review. Sacramento: California Institute for Mental Health, 2005.

26. Walker JS, Gowen K, Jivanjee P, et al. Pathways to Positive Futures: State-of-the-Science Conference Proceedings (Part 1). Portland, OR: Portland State University, Research and Training Center for Pathways to Positive Futures, 2013.

27. Walker JS. A theory of change for positive developmental approaches to improving outcomes among emerging adults with serious mental health conditions. Journal of Behavioral Health Services \& Research, 2015; 42(2).

28. Holburn S, Cea CD. Excessive positivism in personcentered planning. Research and Practice for Persons with Severe Disabilities 2007; 32(3): 167-172.

29. Walker JS, Schutte K. Practice and process in wraparound planning. Journal of Emotional and Behavioral Disorders 2004; 12: 182-192.

30. Walker JS, Schutte K. Quality and individualization in wraparound. Journal of Child and Family Studies 2005; 14: 251-267.

31. Dumbrill G. Parental experience of child protection intervention: A qualitative study. Child Abuse and Neglect 2006; 30: 27-37.
32. Smith B. Child welfare service plan compliance: Perceptions of parents and caseworkers. The Journal of Contemporary Social Services 2008; 89: 521-533.

33. McCammon SL. Systems of care as asset-building communities: Implementing strengths-based planning and positive youth development. American Journal of Community Psychology 2012; 49(3-4): 556-65.

34. Lietz C. Theoretical adherence to family centered practice: Are strengths-based principles illustrated in families' descriptions of child welfare services? Children and Youth Services Review 2011; 33: 888-893.

35. Taylor JE, Taylor JA. Person-centered planning: Evidence-based practice, challenges, and potential for the 21st century. Journal of Social Work in Disability \& Rehabilitation 2013; 12(3): 213-35.

36. Mitchell PF. Evidence-based practice in real-world services for young people with complex needs: New opportunities suggested by recent implementation science. Child Youth Services Review 2011; 33(2): 211-216.

37. Powell BJ, Proctor EK, Glass JE. A systematic review of strategies for implementing empirically supported mental health interventions. Research on Social Work Practice. 2013; 24(2): 192-212.

38. Fixsen DL, Naoom SF, Blase KA, et al. Implementation Research: A Synthesis of the Literature. Tampa, FL: University of South Florida, Louis de la Parte Florida Mental Health Institute, The National Implementation Research Network (FMHI Publication \#231).

39. Oliver P. Purposive sampling. In: V. Jupp (Ed). The SAGE Dictionary of Social Research Methods. London: SAGE Publications, Ltd., 2006, pp. 245-246.

40. Braun V, Clarke V. Using thematic analysis in psychology. Qualitative Research in Psychology 2006; 2: 77-101.

41. Muhr T. ATLAS.ti - A Prototype for the Support of Text Interpretation. Qualitative Sociology 1991; 14(4): S.349-371.

42. Sawyer R. The Cambridge Handbook of the Learning Sciences. New York: Cambridge University Press, 2006.

43. Miller W, Rollnick S. Motivational Interviewing, Third Edition: Helping People Change (Applications of Motivational Interviewing). New York: Guilford Press; 2012. 
44. Barth RP, Lee BR, Lindsey MA, et al. Evidencebased practice at a crossroads: The timely emergence of common elements and common factors. Research on Social Work Practice 2011, 22(1): $108-11$.

45. Bruns EJ, Walker JS, Bernstein AD, et al. Family voice with informed choice: Coordinating wraparound with research-based treatment for children and adolescents. Journal of Clinical Child and Adolescent Psychology 2014; 43(2): 256-269.

46. Gullan RL, Power TJ, Leff SS. The role of empowerment in a school-based community service program with inner-city, minority youth. Journal of Adolescent Research 2013; 28(6): 664-689.

47. Brink AJW, Wissing MP. Review article: A model for a positive youth development intervention. Journal of child and adolescent mental health 2012; 24(1): 1-13.

48. Fraker T, Rangarajan A. The social security administration's youth transition demonstration projects. Journal of Vocational Rehabilitation 2009; 30: 223-240.

49. Morton MH, Montgomery P. Youth empowerment programs for improving adolescents' self-efficacy and self-esteem: A systematic review. Research on Social Work Practice 2012; 23(1): 22-33.
50. Frechtling JA. Logic Modeling Methods in Program Evaluation. San Francisco: Jossey-Bass, 2007.

51. Rogers PJ, Petrosino A, Huebner TA, et al. Program theory evaluation: Practice, promise, and problems. New Directions for Evaluation 2000; 87: 5-13.

52. Savaya R, Waysman M. The logic model: A tool for incorporating theory in development and evaluation of programs. Administration in Social Work 2005; 29(2): 85-104.

53. US Government Accountability Office. Young adults with serious mental illness: Some states and federal agencies are taking steps to address their transition challenges. GAO Publication No. 08-678, Washington DC: Author, 2008.

54. Pottick KJ, Bilder S, Vander Stoep A, et al. US patterns of mental health service utilization for transition-age youth and young adults. Journal of Behavioral Health Services \& Research 2008; 35(4): 373-389.

55. Frazier SL, Bearman SK, Garland AF, et al. Dissemination and implementation in children's mental health: Closing the research to training gap. In: RS Beidas, PC Kendall (Eds.). Dissemination and Implementation of Evidence-Based Practices in Child and Adolescent Mental Health. New York: Oxford University Press, 2014, pp. 98-124.

This manuscript was published online May 2015 in the Journal of Behavioral Health Services \& Research. The final publication is available at Springer via http://link.springer.com/article/10.1007/s11414-015-9465-8.

This activity is supported by a grant funded by both the National Institute of Disability, Independent Living, and Rehabilitation Research, and the Center for Mental Health Services Substance Abuse and Mental Health Services Administration, United States Department of Health and Human Services (NIDILRR grant 90RT5030). NIDILRR is a Center within the Administration for Community Living (ACL). The content does not necessarily represent the policy of NIDILRR, ACL, HHS, and you should not assume endorsement by the Federal Government.

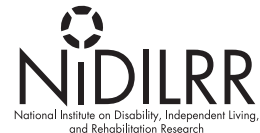

SAMHSA 